\title{
Influence of automatic feeding systems on design and management of dairy farms
}

\author{
Francesco Da Borso, ${ }^{1}$ Alessandro Chiumenti, ${ }^{1}$ Maurizia Sigura, ${ }^{1}$ Andrea Pezzuolo ${ }^{2}$ \\ ${ }^{1}$ Department of Agricultural, Food, Environmental and Animal Sciences, University of Udine; \\ ${ }^{2}$ Department of Land, Environment, Agriculture and Forestry, University of Padova, Legnaro (PD), Italy
}

\begin{abstract}
During the last decades, many dairy farmers have actively advanced their farms toward automation. Automatic concentrate dispensers and automatic milking systems have been utilised for years, and several manufacturers have introduced automatic feeding systems (AFS). AFSs allow for the increase in frequency of feed distribution with significant advantages in terms of health and production. Furthermore, they provide a reduction of man labour related to preparation of feed, distribution, and propelling the ration closer to the feeding rack.

The present research was focused on the monitoring of a dairy farm, located in the Veneto region of Italy, during the transition from a conventional feeding system (CFS), based on a tractor operated mixing wagon, to an automatic system equipped with stationary feeding hoppers, mixing unit, and distribution wagon operating on rail. The article reports a comparative analysis of the structural modifications required for the adoption of AFS, including an analysis of the AFS/CFS systems based on their functionality, energy, and man labour requirements. In the case study, AFS represented an affordable way to reduce covered area of the housings, as a result of the reduction in width of foraging lane and the reduction of manger front length. In addition, AFS demonstrated a reduction in labour requirements and improvement of quality and consistency of work when feeding total mixed ration. Finally, the
\end{abstract}

Correspondence: Francesco Da Borso, Department of Agricultural, Food, Environmental and Animal Sciences, University of Udine, via delle Scienze 206, 33100 Udine, Italy.

E-mail: francesco.daborso@uniud.it

Key words: Dairy cow; housing systems; automatic feeding systems; total mixed ration; behaviour.

Acknowledgements: we are grateful to farmer Mr. Michele Durante and Mr. Enrico Ballan for their useful and kind collaboration. The authors would like to thank Dr. Penny Lazo for the professional and kind support for the proof reading and English language editing of the paper.

Received for publication: 30 November 2016.

Accepted for publication: 25 March 2017.

(C) Copyright F. Da Borso et al., 2017

Licensee PAGEPress, Italy

Journal of Agricultural Engineering 2017; XLVIII(s1):642

doi:10.4081/jae.2017.642

This article is distributed under the terms of the Creative Commons Attribution Noncommercial License (by-nc 4.0) which permits any noncommercial use, distribution, and reproduction in any medium, provided the original author(s) and source are credited. research was addressed to study dairy cow behaviour. A method for monitoring the feeding, resting, and standing indexes was applied to the CFS farm. As a preliminary result of this activity, a positive correlation between cow resting activity and milk production was discovered.

\section{Introduction}

Automation of feeding using automatic feeding systems (AFS) is becoming increasingly popular as well, and in 2013 it was estimated that around thousand systems were in operation throughout Europe (Bonsels et al., 2013).

Various technical approaches have been developed for automatic feeding of cattle, and it is possible to distinguish among three automation stages: i) mixing - distribution; ii) filling mixer mixing - distribution; iii) unloading and transport - filling mixer mixing - distribution. In the Stage I, a stationary feed mixer must be filled by mobile equipment from bunker silos. The advantage of this variant is that cows can be fed automatically several times a day, but filling the feed mixer still requires time. Stage II is characterised by the capability to feed all cows several times a day, while the farmer is no longer hindered by fixed filling and feeding times. Fully automatic feeding in Stage III has so far only been executed in conjunction with tower or deep silos, but these must be classified as comparatively expensive in construction and power consumption (Haidn, 2014).

The main advantage of AFS is the possibility to supply a total mixed ration (TMR) with a high frequency and a low labour requirement, whilst farms that feed with conventional feeding systems (CFS) commonly supply TMR only once or twice a day and require more labour combined with a rigid work schedule. However, an additional important reason for farmers to invest in this technology is the possibility of being able to feed performance groups only portions of the total dairy ration several times per day.

AFS permits increased frequency of feed distribution (up to 15 cycles per day) with a consequent optimisation of dry matter ingestion by the animals, assisting to maintain a higher stability of ruminal $\mathrm{pH}$ with significant advantages in terms of health and production (DeVries et al., 2005). Moreover, a higher frequency reduces the permanence time of feed on the manger with reduced possibility of contamination and of anomalous fermentations (Wagner-Storch and Palmer, 2003).

Multiple researches have studied the consequences of the feeding frequency (Oostra, 2005; Mantysaari et al., 2006; Riva et al., 2013). Supplying roughage once or twice a day results in a feeding pattern that is characterised by daily peaks of visits to the feeding fence immediately after the feed delivery. However, increasing the feeding frequency stimulates the visits to the feeding fence and leads to a more evenly distributed visiting/feeding pattern. 
The integration of AFSs in the layout of new or existing barns raises questions with respect to the location and capacity of the components of an AFS. Transitioning to an automated TMR feeding system requires expensive investments, even if a fairly wide range of models different in complexity and cost became available on the market. On the other hand, robots seem to require less space and power than a standard tractor-pulled mixer wagon (Bisaglia et al., 2008; Nydegger and Grothmann, 2009).

The present work features a first phase represented by a survey of the commercial solutions offered in the Italian market, in order to assess the effect of the introduction of the AFS on the layout of free stall cow farms. A second phase consisted of experimental observations in a farm transitioning from a traditional TMR feeding system to the AFS. Operation times, energy consumption, and costs for various tasks were determined from both traditional and automated systems. Additionally, a methodology for the evaluation of animal behaviour was developed and implemented, and the present work aims to report the partial results obtained in the monitoring of the traditional system, while future tests with the AFS will complete the study. The final objective, however, will be optimisation of the methodology to relate behaviour data of single cows with their production performances.

\section{Materials and methods}

\section{Preliminary overview of the automatic feeding systems technologies}

The first phase of the study was represented by a detailed literature survey and analysis of the technical information provided by the manufacturers of AFS technologies.

The main parameters obtained in this phase were the barn layout and accessory requirements for farms intending to implement the AFS (dimension of equipment, required room for operation, covered surfaces, feeding front).

For each typology of AFS, based on a structural model for a hypothetical dairy farm with 120 lactating cows, specific area indexes (expressed as $\mathrm{m}^{2} \mathrm{cow}^{-1}$ ) were calculated as ratio between the covered area (total, without areas for the preparation of the total mixed ratio) and number of cubicles.

\section{Experimental site and design}

The study was performed in a private dairy farm located near Treviso in Northeast Italy. The farm was characterised by a freestall system, housing 126 lactating cows, with concrete floor and surface scrapers for a frequent removal of manure. The barn features natural ventilation and fans are installed on the ceiling to face high temperatures during summer time. Installed in the centre of the housing is a single AMS, single box type. The average milk production in 2015 resulted in $8435 \mathrm{~kg} \mathrm{cow}^{-1}$. The prevailing breed was Holstein-Friesian.

The ration was composed by cereal silage [51.0\% dry matter (DM)], maize flour and cottonseed (24.3\% DM), concentrate (13.2\% DM), and hay (11.5\% DM). Each animal was fed, on daily basis, with $12.2 \mathrm{~kg}$ of cereal silage, $5.7 \mathrm{~kg}$ of maize flour and cottonseed, $3.1 \mathrm{~kg}$ of concentrate, and $2.7 \mathrm{~kg}$ of hay. While concentrate was supplied by the automatic dispenser in the AMS, the remaining components were mixed to obtain TMR. After the mixing of the components, the TMR presented a volumic mass of 245 $\mathrm{kg} \mathrm{m}^{-3}$, with a DM content of $50 \%$.

\section{Feeding systems}

In the initial configuration, the farm adopted traditional equipment for the preparation of the TMR. CFS, in particular, featured a TMR feeding unit represented by a $10 \mathrm{~m}^{3}$ nominal volume trailed mixer wagon equipped with a single, vertical axis auger. A 4WD, $80 \mathrm{~kW}$, nominal power tractor was dedicated to operate the wagon. A telescopic handler machine $(73 \mathrm{~kW})$ was utilised for loading the mixer with the components of the ration. In the first configuration, the distribution of the TMR was performed once daily.

The AFS, installed in a second time and considered for the comparison, featured a self-loading device with 3 feed-stations and a self-propelled chopping-mixing-feeding unit $10 \mathrm{~m}^{3}$ nominal volume, and equipped with $\mathrm{n}$. 2 vertical augers. The distribution was performed by a dedicated wagon loaded by feed conveyor belt. This unit, characterised by a nominal volume of $3 \mathrm{~m}^{3}$, was suspended on an overhead rail and maneuvered independently along the track. The entire system was powered by electric motors and offered the possibility of varying the ration several times per day according to the requirements of the dairy farm.

In both configurations, the TMR was $10 \mathrm{~m}^{3}$ day $^{-1}$.

\section{Cow behaviour}

Several technical visits and preliminary tests were performed to set up the observation method. The preliminary test consisted in a monitoring of a full week. The results of the monitoring reported in the paper are referred to a interval of $24 \mathrm{~h}$ of continuous observation, precisely on June the $1^{\text {st }}$, with a mean air temperature of $20.3^{\circ} \mathrm{C}$ (minimum $13.6^{\circ} \mathrm{C}$ and maximum $27.6^{\circ} \mathrm{C}$ ) and relative humidity ranging from $44 \%$ to $100 \%$.

The observation of the cows' behaviour was direct, by visual monitoring of the group and continuous registration for $24 \mathrm{~h}$, in order to detect the number of cows present at the feeding area $\left(C_{f}\right)$, in the cubicles in resting position $\left(C_{r}\right)$ and in the cubicles in standing position $\left(C_{S}\right)$. The cows in milking phase were monitored by software for the management and control of the feeding robot. The software also provided individual information for each animal.

The behavioural indices named cow feeding index (CFI), cow resting index (CRI), cow standing index (CSI) were then calculated with the following equations (Wagner-Storch and Palmer, 2003; Mattachini et al., 2011):

$$
\begin{aligned}
& C F I(\%)=\frac{C_{f} \cdot 100}{C_{f}+C_{l}+C_{s}} \\
& C R I(\%)=\frac{C_{l} \cdot 100}{C_{f}+C_{l}+C_{s}}
\end{aligned}
$$

$$
C S I(\%)=\frac{C_{s} \cdot 100}{C_{f}+C_{l}+C_{s}}
$$

Furthermore, n. 6 cows, homogeneous in terms of physiological and reproductive characteristics (first lactation, days in milking 120-180) and production performance (milk average production of 29.0-33.7 $\mathrm{kg} \mathrm{day}^{-1}$ ), were individually observed in order to estimate the distribution of time among the behavioural conditions: feeding, resting, standing. These values were correlated by linear regression to individual milk production obtained in the same period. 


\section{Results and discussion}

The factor with the highest influence on the layout of the housings is represented by the width of the feeding alley, reduced to 1 $\mathrm{m}$ in case of conveyor belt system (AFS type 1), while it remains in the range between $2.6 \mathrm{~m}$ and $3.2 \mathrm{~m}$ for other systems (Figure 1 and Table 1). Consequently, specific area indexes resulted of 7.2 $\mathrm{m}^{2} \mathrm{cow}^{-1}$ for AFS type 1 and of 8.0 and $8.3 \mathrm{~m}^{2} \mathrm{cow}^{-1}$ for AFS type 3 and type 2, respectively. The studied AFS is present in a housing featuring 4 rows of cubicles, where the specific area index results of $8.8 \mathrm{~m}^{2}$ cow $^{-1}$ (comprehensive of the milking area occupied by the AMS) and the feeding front is reduced to $0.44 \mathrm{~m} \mathrm{cow}^{-1}$, which allowed to perform n. 4 feed distributions per day and with a simplified barrier (post and rail feed barrier), replacing the conventional type (head lock feed barrier).

The main requirement of man labour for CFS is represented by the loading of the wagon $\left(0.98 \mathrm{~h} \mathrm{day}^{-1}\right)$, followed by cutting/mixing $\left(0.67 \mathrm{~h} \mathrm{day}^{-1}\right)$, transportation $\left(0.45 \mathrm{~h} \mathrm{day}^{-1}\right)$ and distribution $\left(0.40 \mathrm{~h} \mathrm{day}^{-1}\right)$. In terms of man labour, the AFS determined significant advantages, with a total requirement of labour of $1.02 \mathrm{~h}$ day ${ }^{-1}$, compared to $2.5 \mathrm{~h}^{\text {day }}{ }^{-1}$ of CFS. The AFS, in fact, requires an operator only for the loading of the feeding hoppers, performed once every three days, along with control of the system (Pezzuolo et al., 2016).

Energy consumption for CFS, computed considering installed power and operation times, resulted of $94.00 \mathrm{kWh}^{\text {day }}{ }^{-1}$ for the loading, $104.76 \mathrm{kWh} \mathrm{day}^{-1}$ for the cutting/mixing operation (the most demanding phase), and $47.89 \mathrm{kWh} \mathrm{day}^{-1}$ for transportation and distribution. The total consumption of the CFS was 246.64 $\mathrm{kWh}$ day $^{-1}$. For the AFS the most demanding phase was represented by cutting/mixing, with an energy consumption of $30.0 \mathrm{kWh}$ day ${ }^{-1}$, followed by the loading $26.27 \mathrm{kWh}$ day $^{-1}$, while transportation $\left(4.66 \mathrm{kWh} \mathrm{day}^{-1}\right)$ and distribution $\left(7.12 \mathrm{kWh}^{-1 a y^{-1}}\right)$ required less energy. In general, total energy consumption of the AFS was $68.05 \mathrm{kWh}$ day $^{-1}$.

The results of the animal behaviour analysis, reported here, refer to the status of CFS prior to the transformation, hence, with one daily distribution of the TMR by wagon (Figure 2). The resting phase in cubicles was prevalent during the night, when CRI was between 75.0 and $95.0 \%$ for more than $6 \mathrm{~h}$, thus within a range of values considered desirable for cows welfare (Provolo and Riva, 2009). Activity in the feeding alley was mainly recorded during daytime, with a peak of $78.8 \%$ recorded after the feed distribution at 01:00-02:00 p.m.

As expected, the indexes referred to the main activities - feeding and rest - revealed a complementary trend. In fact, the feeding peaks are followed, with a delay of 1-2 $\mathrm{h}$, by rest peaks.

Milking was performed mainly during daytime from 8:00 a.m. to $6: 00$ p.m. Accordingly, occupation of cubicles not corresponding to rest (standing) was observed during the morning hours before the distribution of the TMR, with the CSI ranging from 16.1
A

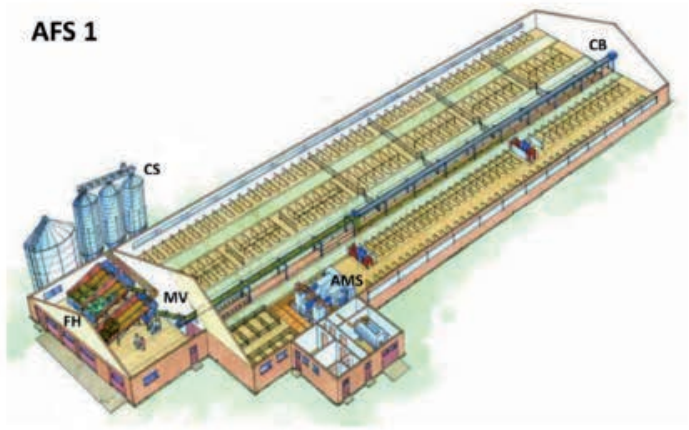

B

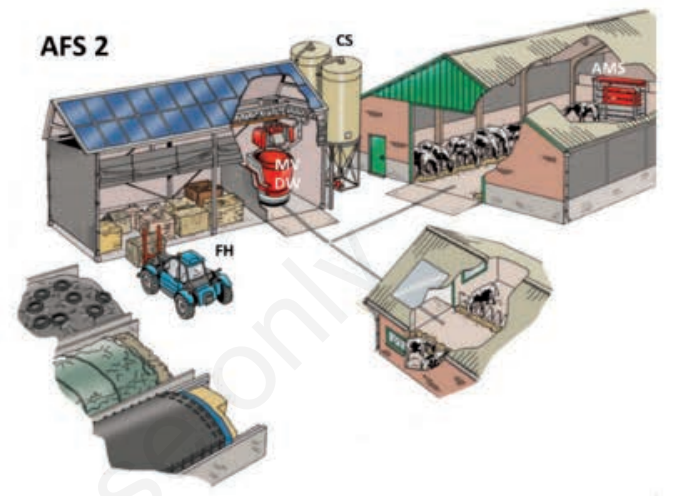

C

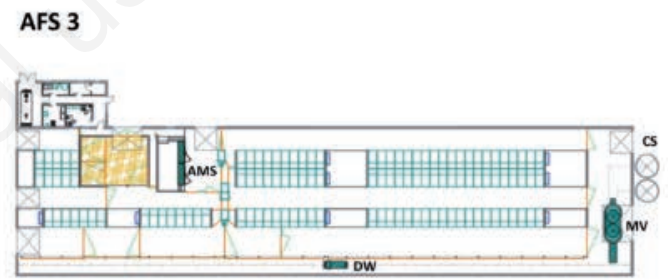

D

AFS studied

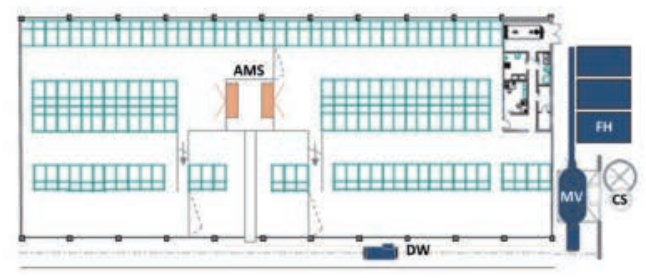

Figure 1. Brief description of different automatic feeding systems (AFS): A) AFS 1 - conveyor belts (by Pellon Group Oy); B) AFS 2 - self-propelled feeding wagon (by Lely Holding S.à.r.l.); C) AFS 3 (by GEA Farm tech. GmbH); and D) the AFS object of the study (by DeLaval SpA) - rail guided feeding wagon. FH, feeding hoppers; CS, concentrate silo; $\mathrm{MV}$, mixing vessels; $\mathrm{CB}$, conveyor belt; DW, distribution wagon; AMS, automatic milking system.

Table 1. Main dimensional criteria of free stall barns for 126 lactating cows with automatic feeding systems operating 4 feed distributions per day.

\begin{tabular}{lccccc} 
Parameter & Unit & AFS type 1 & AFS type 2 & AFS type 3 & AFS studied \\
Description & $\mathrm{m}$ & $\begin{array}{c}\text { Conveyor } \\
\text { belt }\end{array}$ & $\begin{array}{c}\text { Self-propelled } \\
\text { feed wagon }\end{array}$ & $\begin{array}{c}\text { Suspended } \\
\text { rail-guided feeding wagon }\end{array}$ & $\begin{array}{c}\text { Suspended } \\
\text { rail-guided feeding wagon }\end{array}$ \\
Distribution alley width & 1.0 & 3.2 & 2.6 & 2.6 \\
\hline Specific area index (total) & $\mathrm{m}^{2} \mathrm{cow}^{-1}$ & 7.2 & 8.3 & 8.0 & 8.8 \\
Specific feed manger space & $\mathrm{m} \mathrm{cow}^{-1}$ & 0.48 & 0.48 & 0.48 & 0.44 \\
\hline
\end{tabular}

AFS, automatic feeding systems. 
to $26.7 \%$. The plots of Figures 3-5 correlate the behaviour of n. 6 cows individually observed, with their milk production. From these preliminary data, referred only to the CFS before the installation of the AFS, the absence of positive correlation between the comprehensive time of permanence at the feeding fence and the production of milk can be observed. This aspect should be further investigated in the second phase of the study that will be performed with the AFS at full regime. It is probable that cows remain at the feeding fence without continuing feeding: shorter and more frequent visits at the feeding fence could determine an advantage (De Vries et al., 2005; Belle et al., 2012).

An interesting observation to note is that the resting behaviour was the singular only phase to exhibit a positive correlation with the milk production $\left(\mathrm{R}^{2}=0.78\right)$. The cows that rested from 14.6 to $16.4 \mathrm{~h}$ of daytime had a milk production from 32.8 to $33.7 \mathrm{~kg}$ day ${ }^{-1}$. Several authors report the benefit of lying time correspond to cow comfort, health, and level of milk production and suggest about $14 \mathrm{~h} \mathrm{day}^{-1}$ as optimal duration (Calegari et al., 2012). From these preliminary results, the behaviour of standing in the cubicles seems inversely correlated to milk production (Belle et al., 2012). The cows that were standing for more than $2 \mathrm{~h}$ per day were characterised by a milk production lower than $30 \mathrm{~kg}$ day $^{-1}$.

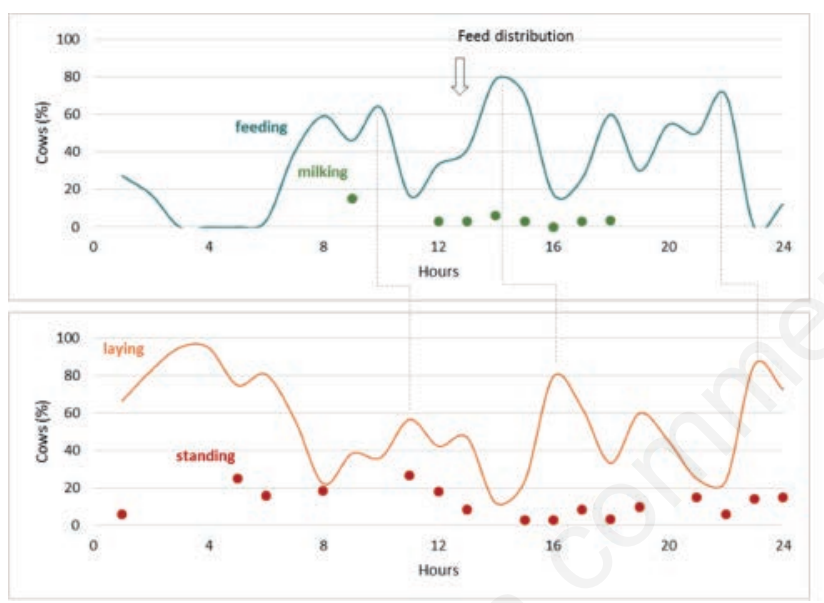

Figure 2. Hourly behavioural index (feeding, resting and standing index) observed with a conventional feeding system operating once daily between 12:00 and 01:00 p.m. Percentage of cows visiting automatic milking system are also indicated.

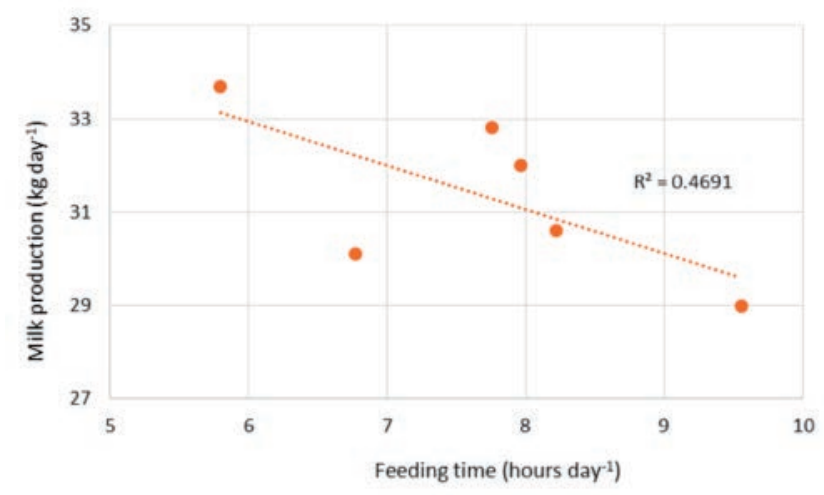

Figure 3. Correlation between cow feeding behavioural index and daily milk production (for n. 6 cows).

\section{Conclusions}

Primary results of the study demonstrated that the AFS can represent a substantial and compelling solution for the dairy cows sector. The AFS can be introduced in existing farms, but it requires important structural evolution in new realisations such as reduction of the dimensions of feeding alley, reduction of specific feeding front, as well as a simplified feed barrier.

The study revealed a reduction of man labour and energy consumption passing from CFS to AFS. Furthermore, the AFS actuated by electric energy can be powered by renewable energies (photovoltaic, cogeneration).

The methodology adopted for the evaluation of the behaviour of cows, in relation to milk production and quality, proved to be effective and precise but remarkably demanding in terms of labour. Data were obtained only with the CFS, in a mild, late spring period, and different environmental conditions could affect the behaviour of the animals. Further tests will be performed with the AFS in comparable ambient conditions.

An automated system, similar to that developed by Porto et al. $(2013,2015)$, for the efficient detection of position and activity of

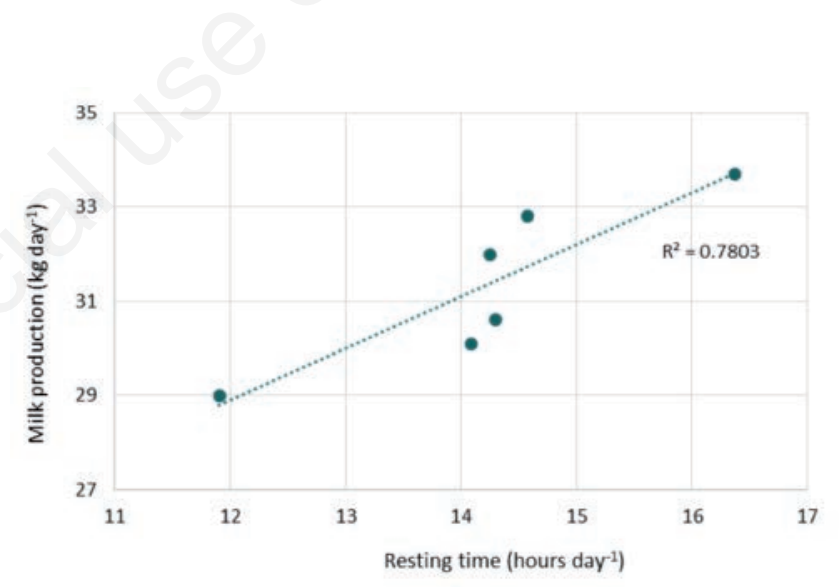

Figure 4. Correlation between cow resting behavioural and daily milk production (for $n .6$ cows).

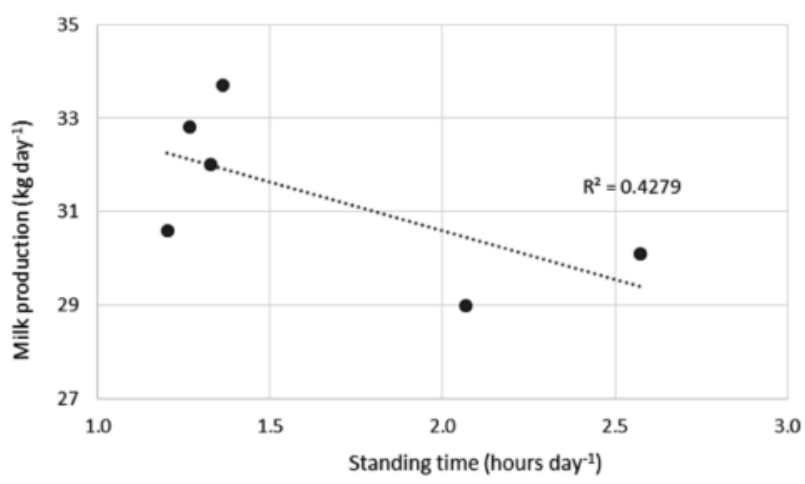

Figure 5. Correlation between behavioural index (cow feeding, cow resting and cow standing index) and daily milk production (for $n .6$ cows). 
the animals should be adopted which will allow for initiation of a further research phase for collecting data with an installed and functioning AFS.

Additionally, it is important to underline that cows have more behavioural freedom when automated feeding systems are integrated with automated milking systems, an aspect that should be subject to further investigation.

\section{References}

Belle Z., André G., Pompe J.C.A.M. 2012. Effect of automatic feeding of total mixed rations on the diurnal visiting pattern of dairy cows to an automatic milking system. Biosyst. Engine. 111:33-9.

Bisaglia C., Pirlo G., Capelletti M. 2008. A simulated comparison between investment and labour requirements for a conventional mixer feeder wagon and an automated total mixed ration system. pp 1-7 in Proceeding of International Conference on "Agricultural Engineering \& Industry exhibition - AgEng", June 23-25, Crete, Greece.

Bonsels T., Malkow-Nerge K., Priesmann T. 2013. Antworten zur Automatischen Futtervorlage beim Rind. First edition. DLG e.V., Frankfurt am Main, Germany.

Calegari F., Calamari L., Frazsi E. 2012. Misting and fan cooling of the rest area in a dairy barn. Int. J. Biometeorol. 56:287-95.

De Vries T.J., von Keyserlingk M.A.G., Beauchemin K.A. 2005. Frequency of feed delivery affects the behavior of lactating dairy cows. J. Dairy Sci. 10:3553-62.

Haidn B. 2014. Automatisches Füttern bei Milchkühen Verfahrenstechnik, Arbeitswirtschaft und Kosten. In: Automatisches Füttern im rinderhaltenden Betrieb. Bayerische Landesanstalt für Landwirtschaft, Freising, Germany, pp 7-20.
Mantysaari P., Khalili H., Sariola J. 2006. Effect of feeding frequency of a total mixed ration on the performance of highyielding dairy cows. J. Dairy Sci. 11:4312-20.

Mattachini G., Riva E., Provolo G. 2011. The lying and standing activity indices of dairy cows in free-stall housing. Appl. Animal Behav. Sci. 129:18-27.

Nydegger F., Grothmann A. 2009. Automatic feeding of cattle: results of a survey on the state of the art. ART-Berichte 710:8.

Oostra H.H. 2005. The effects of feeding frequency on waiting time, milking frequency, cubicle and feeding fence utilisation for cows in an automatic milking systems. Acta Agric. Scand. Sect. Anim. Sci. 4:158-65.

Pezzuolo A., Chiumenti A., Sartori L., Da Borso, F. 2016. Automatic feeding systems: evaluation of energy consumption and labour requirement in north-east Italy dairy farm. Engine. Rural Develop. 15:882-7.

Porto S.M.C., Arcidiacono C., Anguzza U., Cascone G. 2013. A computer vision-based system for the automatic detection of lying behaviour of dairy cows in free-stall barns. Biosyst. Engine. 115:184-94.

Porto S.M.C., Arcidiacono C., Anguzza U., Cascone G. 2015. The automatic detection of dairy cow feeding and standing behaviours in free-stall barns by a computer vision-based system. Biosyst. Engine. 133:46-55.

Provolo G., Riva E. 2009. One year study of lying and standing behaviour of dairy cows in a free-stall barn in Italy. J. Agricult. Engine. 2:22-33.

Riva E., Mattachini G., Bava L., Sandrucci A., Tamburini A., Provolo G. 2013. Influence of feed delivery frequency on behavioural activity of dairy cows in freestall barns. J. Agricult. Engine. 44:197-202.

Wagner-Storch A.M., Palmer R.W. 2003. Feeding behavior, milking behavior and milk yields of cows milked in a parlor versus an automatic milking system. J. Dairy Sci. 86:1494-502. 